\title{
OS DESAFIOS DA CRIAÇÃO DE COTAS PARA PRETOS, PARDOS E INDÍGENAS (PPI) NAS UNIVERSIDADES BRASILEIRAS
}

\author{
Gretha Leite Maia ${ }^{1}$
}

\begin{abstract}
RESUMO
Trata-se de um estudo analítico dos desafios de criação da Lei de Cotas no Brasil, especificamente a ocupação de vagas em reserva para estudantes Pretos, Pardos e Indígenas, os cotistas PPI. Parte do reconhecimento da necessidade de uma reserva de vagas para determinados segmentos sociais historicamente excluídos do Ensino Superior no Brasil, considerando dados obtidos nos diversos censos universitários e gerais. Examina os dispositivos normativos da Lei no 12.711/2012 e da Portaria MEC no 18/2012, que lhe regulamenta, especificamente, no que dispõe de vagas para Pretos, Pardos e Indígenas. Analisa casos específicos, divulgados na mídia, ocorridos nas Universidades Federais do Ceará, do Rio de Janeiro e da Grande Dourados. Conclui que a autodeclaração, enquanto documento necessário à solicitação de matrícula em vaga reservada para PPI, pode ser contrastada por comissões de heteroidentificação em um procedimento administrativo integrante do procedimento de matrícula, posto que tal procedimento complementar contribui para a efetividade da política afirmativa.
\end{abstract}

Palavras-chave: Ensino Superior; Lei de Cotas; pretos, pardos e indígenas.

\section{CREATION CHALLENGES OF A RACIAL QUOTA POLITICS IN BRAZILIAN UNIVERSITIES}

\section{ABSTRACT}

This article aims to analyze the challenges of a racial quota politic in Brazilian universities. As an affirmative action, it proposes to reserve places in publics universities for people of color (black, mixed race and Brazilian natives) by self-declaration of race. Previous researches demonstrated that people of color in Brazil had been systematically excluded from Higher education. This article analyses cases that show the challenges in some Brazilian universities: Federal University of Ceara, Federal University of Rio de Janeiro and Federal University of Grande Dourados. These cases show one specific challenge when implementing the politic: who has the right to ask for a reserved place? Who benefits from such affirmative action? It concludes that the self-declaration race is not enough to guarantee that the politic will achieve what it intended and that others procedures are required to secure its effectiveness.

Keywords: Higher education; racial quota; people of color; native brazilian.

RECEBIDO EM: 28/10/2019

ACEITO EM: 20/11/2020

1 Universidade Federal do Ceará - Faculdade de Direito. Rua Meton de Alencar, 1269/1270. Centro. Fortaleza/CE, Brasil. CEP 60035-160. http://lattes.cnpq.br/9623562350572470. http://orcid.org/0000-0002-6908-1772. grethaleitemaia@gmail.com 


\section{INTRODUÇÃO}

A Lei no 12.711, de 29 de agosto de 2012, estabeleceu um programa especial de acesso ao ensino público federal superior e médio por meio de reserva de vagas nas universidades federais e nas instituições federais de ensino técnico de nível médio (BRASIL, 2012a). A Lei de Cotas, como ficou conhecida, foi regulamentada pelo Decreto no 7.824, de 11 de outubro de 2012 (BRASIL, 2012b), e pela Portaria MEC no 18, de 11 de outubro de 2012 (BRASIL, 2012c). Trata-se de uma política pública veiculada por lei específica, que tem na definição dos beneficiários das cotas um de seus maiores desafios. O objetivo deste estudo é destacar os desafios do enquadramento dos chamados cotistas PPI: pretos, pardos e indígenas. Para tanto, foram escolhidos e analisados casos com ampla veiculação na imprensa, ocorridos na Universidade Federal da Grande Dourados - UFGD -, na Universidade Federal do Rio de Janeiro - UFRJ - e na Universidade Federal do Ceará - UFC -, para a qual se dará ênfase. Trata-se de um estudo analítico, a partir de uma leitura dos dispositivos normativos e dos questionamentos que surgiram desde os primeiros processos seletivos organizados em obediência à reserva de vagas a partir de 2013, bem como das manifestações ministeriais e judiciais já havidas, como a Ação Civil Pública no 0803149-12.2018.4.05.8100, que tramitou em 1aa instância na 3ạ Vara da Justiça Federal, sessão Ceará (JUSTIÇA FEDERAL, 2019).

Conforme já apresentado em estudo anterior ${ }^{2}$, a reserva de vagas públicas no Ensino Superior brasileiro é uma política afirmativa orientada pelo princípio de igualdade no acesso à educação e concebida a partir da proposta de um reforço da responsabilidade social da Universidade, tal como defendido por Santos (2011). Nessa perspectiva, convém lembrar que a Lei de Cotas somente terá alguma eficácia se se fizer acompanhar por um amplo programa de assistência estudantil, como restaurantes universitários, linhas intercampi e intracampi e auxílios-moradia e permanência, programas que viabilizem a permanência, conforme Sousa Júnior (2012). Para esta lei ser instituída, foi precedida por estudos que buscavam dados que desvelassem a realidade do Ensino Superior brasileiro, especialmente para definir objetivos e critérios para a reserva. Esses dados indicam um cenário em que aproximadamente $71,4 \%$ da população universitária estava vinculada a instituições privadas (EBC, 2014). Diante deste dado, verifica-se que há uma oferta de vagas no ensino público e gratuito três vezes menor que a oferta privada, o que possibilita uma primeira afirmação de que o Ensino Superior no Brasil é majoritariamente privado e que uma discussão sobre democratização de acesso deve investigar também os dados relativos às matrículas financiadas pelo Estado brasileiro por meio de programas como Fies e Prouni.

Tendo como base ainda os censos universitários e dados do IBGE, conforme pesquisa divulgada pela Agência Pública - EBC -, 54,5\% dos estudantes do Ensino Superior na rede pública pertencia à parcela $20 \%$ mais rica da população brasileira - com renda média por pessoa da residência de $\mathrm{R} \$ 2,9$ mil em 2004. Dez anos depois, esse grupo

Conforme já explorado em MAIA, Gretha Leite; MELO, César. Lei de Cotas no Ensino Público: fundamentos, dispositivos normativos e desafios de implementação. Revista de Direito Administrativo e Infraestrutura, v. 1, p. 165-184, 2017. Disponível em: http://https://www.thomsonreuters.com.br/pt/juridico/webrevistas/RDAl-revista-direito-admnistrativo-infraestrutura.html. Acesso em: 20 set. 2019. 
ocupava $36,4 \%$ das vagas nas universidades públicas. A proporção de estudantes pertencentes ao quinto mais pobre da população, com renda per capita média de $\mathrm{R} \$ 1$ 192, era 1,2\% em 2004 e chegou a 7,6\% dos alunos de faculdades públicas em 2014 (AGÊNCIA PÚBLICA, 2015). Os dados indicam uma tendência de modificação no perfil socioeconômico da população universitária na rede pública.

Seria preciso, no entanto, questionar esse percentual por curso. É possível, mesmo sem ter acesso a estes dados, afirmar que determinada parcela da população mais rica tem interesse por cursos específicos das áreas médica, jurídica e das engenharias. Considerando essa possibilidade, os percentuais de ocupação de vagas por renda familiar ou formação escolar na rede pública nos cursos das áreas de Ciências e de Humanidades são, portanto, diferentes. Assim, a política de cotas não teria chegado a modificar o perfil socioeconômico dos cursos nas grandes áreas de Ciências, Educação e Humanidades por exemplo, nos quais o percentual de egressos da escola pública é maior do que os $50 \%$ estabelecidos pela Lei de Cotas. A concorrência por vaga, sobretudo de Medicina, e a quase integralidade das denúncias de ocupação indevida de vagas precisamente neste curso, entretanto, sinaliza o que está em disputa.

Este artigo analisa questões relativas à ocupação de vaga PPI e ao critério de enquadramento dos beneficiários. A previsão normativa, como se verá, é a autodeclaração. Assim, a pergunta de partida deste estudo é: A autodeclaração é um documento suficiente para o enquadramento do beneficiário como PPI? É possível a introdução de "heteroprocedimentos" que complementem ou contrastem a autodeclaração? Quais os critérios para este enquadramento? Quem deve definir a condição de PPI para fins de ocupação de uma vaga numa Universidade federal brasileira?

Os tópicos apresentados a seguir estruturaram-se a partir da disponibilidade de alguns dados e da indisponibilidade de outros, bem como de casos que foram veiculados em mídias de amplo acesso e por meio de análise de sentença emitida em processo judicial público.

\section{FUNDAMENTOS}

Em uma pesquisa rápida percebe-se que a discussão da Lei de Cotas no Brasil se concentrou na fixação de um critério racial para a ocupação das vagas em reserva. Embora o critério principal do recorte seja a frequência à rede pública de Ensino Médio, o assunto que mais provoca discussão é a previsão de cotas raciais a partir da autodeclaração do candidato em um país miscigenado. Os argumentos envolvem questões filosóficas, políticas, econômicas e históricas, dividindo opiniões ao longo dos últimos anos.

Os estudos que precederam a aprovação de uma Lei de Cotas no Brasil para autodeclarados pretos, pardos e indígenas apoiam-se em dados estatísticos e em uma específica compreensão da inserção do negro em uma sociedade de mão de obra assalariada, sustentada há mais de meio século por Florestan Fernandes (2008). Trata-se de um problema que esteve na pauta de discussão no Brasil durante todo o século 20 e ocupou parte da inteligência brasileira, sem que se houvesse elaborado uma política correspondente aos resultados destes estudos. Costa (2010), analisando os impactos da abolição, ressalta a inexistência de qualquer iniciativa para a integração dos recém-libertos às condições de pertencimento em uma sociedade competitiva, denunciando o 
abandono a que foram relegados. Souza (2015, p. 125 et seq.), ao analisar a adoção de um discurso liberal pela elite brasileira ainda no século 19 , identifica no debate sobre a abolição da escravidão o caso mais sintomático de ambiguidade de um pensamento que defendia uma ordem social competitiva em uma sociedade até então escravocrata. Há centenas de opiniões que questionam a possibilidade de ações afirmativas racialistas no Brasil diante da miscigenação da população brasileira. Questiona-se a razão de uma Lei de Cotas raciais em um país cuja população autodeclarada branca é pouco menor do que a população autodeclarada parda e preta ou índia (somadas as três).

Ocorre que há uma população universitária no Brasil na qual esse percentual não se reproduz. Daí a evocação de Souza (2015, p.129) a Florestan Fernandes para lembrar que os negros e os mulatos no Brasil foram precisamente os que tiveram o "pior ponto de partida" na transição da ordem escravocrata à competitiva. Não se afirma, portanto, que os despossuídos se limitem à população de negros e mulatos, mas que há um adicional negativo relacionado estrategicamente à cor quando se pretende instalar uma ordem social burguesa e, portanto, competitiva, no Brasil ao longo do século 20. Neste sentido, há um fundamento histórico para as cotas raciais no Brasil, mesmo que com a inserção dos "pardos" esse critério possa vir a ter mais efeito simbólico do que de reserva de vagas para os pretos e indígenas. A Lei de Cotas, repita-se, não se limita a uma questão racial, mas envolve os problemas relacionados à escola pública brasileira e ao enfrentamento das desigualdades sociais, e isto também é falar sobre o acesso e permanência no Ensino Superior público por uma parcela da população economicamente localizada (famílias com renda per capita igual ou inferior a 1,5 salário mínimo).

Frias (2012) desenvolve um raciocínio similar ao equiparar a cota racial a uma cota social no Brasil. A principal hipótese de seu estudo é que as cotas raciais se justificam apenas como cotas sociais, acrescidas de uma vulnerabilidade a mais. Desta forma, em seu estudo, a hipótese das cotas raciais como cotas sociais vai contra o discurso a favor das cotas raciais, uma vez que ela significa afirmar que as cotas raciais não se justificam como compensação pela escravidão, mas como um instrumento para estabelecer a igualdade de oportunidades, na medida em que a cor da pele ou raça sejam um marcador razoável sobre quem sofreu desvantagens injustas.

No Brasil, o sistema de cotas começa a ser utilizado a partir de meados dos anos 2000 por iniciativas da Universidade do Estado do Rio de Janeiro (Uerj), que foi a primeira universidade do país a criar um sistema de cotas em vestibulares para cursos de Graduação, por meio de uma lei estadual que estabelecia $50 \%$ das vagas do processo seletivo para alunos egressos de escolas públicas cariocas. A UnB foi a primeira instituição pública de Ensino Superior a aderir ao sistema de cotas para negros em 2003. Após dez anos da política, as cotas foram reduzidas de $20 \%$ para $5 \%$ por decisão do Conselho de Ensino, Pesquisa e Extensão - Cepe - da UnB. No caso da UnB, o processo se deu em meio ao uso da autonomia universitária e deliberações colegiadas de seus Conselhos. No caso da Uerj, a medida era de alcance limitado ao Estado do Rio de Janeiro.

A Lei no 12.711/12, entretanto, tem âmbito federal e foi instituída, integralmente, em 2016, e prevê uma revisão em 2022 (BRASIL, 2012a). Considerada por muitos como importante ferramenta de democratização do acesso ao Ensino Superior, a medida não deixou de dividir opiniões, inclusive no âmbito das Universidades Federais. $O$ argumen- 
to que defende uma política de reserva de vagas destaca que o objetivo das cotas é tentar corrigir o que é considerado "injustiça histórica", herdada do período escravista, e que resultou em um menor acesso ao Ensino Superior e a menores oportunidades no mercado de trabalho para negros e índios. A esse argumento somam-se os censos universitários sobre a faixa de renda da população universitária no Brasil.

$O$ fato é que a disputa em torno de vagas concorridas, como as do curso de Medicina, e a diferença de pontuação entre estudantes cotistas e não cotistas, especialmente nas primeiras edições do Sisu pós Lei de Cotas, diferença que está em reversão, parece ter aberto oportunidade para condutas questionáveis de solicitação de enquadramento que não tinham correspondência com a realidade de cor dos candidatos. Às Universidades e ao Ministério Público Federal foram encaminhadas denúncias que, embora numericamente fossem pequenas considerando o número total de ingressantes, eram, muitas vezes, reiteradas e incisivas e, com frequência, acompanhadas de fotos dos candidatos, reforçando a suspeita de ocupação indevida das vagas em reserva. Para o estabelecimento de mecanismos de controle da ocupação de vagas, será preciso, primeiro, um exame nos dispositivos normativos que lhes dão sustentação.

\section{DISPOSITIVOS NORMATIVOS PARA COTAS PPI}

O sistema de cotas nas universidades brasileiras foi estabelecido pela Lei $\mathrm{n}$ o $12.711 / 2012$, em oito artigos de conteúdo dispositivo, e é regulamentado pela Portaria Normativa $n^{\circ} 18$, de 11 de outubro de 2012, do Ministério de Educação. O artigo 1ㅇ da Lei no 12.771/2012 estabelece que as instituições federais de educação superior vinculadas ao Ministério da Educação reservarão, em cada concurso seletivo para ingresso nos cursos de Graduação, por curso e turno, no mínimo 50\% de suas vagas para estudantes que tenham cursado integralmente o Ensino Médio em escolas públicas. $\mathrm{O}$ artigo 3 o aduz que, em cada Instituição Federal de Ensino Superior, as vagas de que trata o artigo 10 da Lei serão preenchidas, por curso e turno, por autodeclarados pretos, pardos e indígenas, em proporção no mínimo igual à de pretos, pardos e indígenas na população da unidade da Federação onde está instalada a instituição, segundo o último censo do Instituto Brasileiro de Geografia e Estatística (IBGE) (BRASIL, 2012a).

Assim, a lei estabeleceu "cotas" dentro da reserva de vagas. Levando-se em conta a totalidade das vagas reservadas, metade será considerada cota para estudantes de escola pública oriundos de famílias com baixa renda e a outra metade para estudantes de escola pública de renda ampla. Essas duas metades (estudante de escola pública renda ampla + estudantes de escola pública renda limitada) passarão por um outro recorte, tendo por referência a autodeclaração dos candidatos como pretos, pardos ou indígenas, em um percentual a ser determinado pelo Censo de cada Estado.

O artigo 60 aduz que o Ministério da Educação e a Secretaria Especial de Políticas de Promoção da Igualdade Racial, da Presidência da República, serão responsáveis pelo acompanhamento e avaliação do programa de que trata esta Lei, ouvida a Fundação Nacional do Índio (Funai). $O$ artigo 70 estabelece que o Poder Executivo promoverá, no prazo de dez anos, a contar da publicação desta Lei, a revisão do programa especial para o acesso de estudantes pretos, pardos e indígenas, bem como daqueles que tenham cursado integralmente o Ensino Médio em escolas públicas, às instituições de educação superior (BRASIL, 2012a). 
A Portaria Normativa $n^{\circ} 18 / 2012$, do MEC, que dispõe sobre as reservas de vagas em instituições federais de ensino, ao estabelecer de forma mais específica os critérios para os cotistas, determina, em seu artigo $3^{\circ}$, que as instituições federais vinculadas ao Ministério da Educação - MEC - que ofertam vagas de educação superior reservarão, em cada concurso seletivo para ingresso nos cursos de Graduação, por curso e turno, no mínimo $50 \%$ de suas vagas para estudantes que tenham cursado integralmente o Ensino Médio em escolas públicas, inclusive em cursos de educação profissional técnica. São determinadas as seguintes condições: I - no mínimo $50 \%$ das vagas de que trata o caput serão reservadas aos estudantes com renda familiar bruta igual ou inferior a 1,5 salário-mínimo per capita; e II - proporção de vagas no mínimo igual à da soma de pretos, pardos e indígenas na população da unidade da Federação do local de oferta de vagas da instituição, segundo o último Censo Demográfico divulgado pelo Instituto Brasileiro de Geografia e Estatística - IBGE -, será reservada, por curso e turno, aos autodeclarados pretos, pardos e indígenas (BRASIL, 2012c).

Ao estabelecer as condições para concorrer às vagas reservadas, a Portaria Normativa $n^{\circ}$ 18/2012 identifica duas seções: uma para estabelecer os critérios de reconhecimento da condição de estudante de escola pública e outra para a condição de renda. A Portaria novamente refere-se à condição de cotista racial a partir da autodeclaração no artigo 14: as vagas reservadas serão preenchidas segundo a ordem de classificação, de acordo com as notas obtidas pelos estudantes, dentro de cada um dos seguintes grupos de inscritos: I - estudantes egressos de escola pública, com renda familiar bruta igual ou inferior a 1,5 salário-mínimo per capita: a) que se autodeclararam pretos, pardos e indígenas; b) que não se autodeclararam pretos, pardos e indígenas; e II - estudantes egressos de escolas públicas, com renda familiar bruta superior a 1,5 salário-mínimo per capita: a) que se autodeclararam pretos, pardos e indígenas; b) que não se autodeclararam pretos, pardos e indígenas e III - demais estudantes (BRASIL, 2012c). Desta forma, foi comum o entendimento de que a cota racial tinha por beneficiários os autodeclarados PPI, e a autodeclaração foi considerada, inicialmente, como o documento suficiente para o enquadramento.

Diante de tais dispositivos normativos, as universidades, como autarquias federais sujeitas ao princípio da legalidade, inicialmente optaram por observar rigorosamente os citados dispositivos. As denúncias e os questionamentos feitos pelo MPF, porém, estabeleceram uma discussão permanente sobre o controle da ocupação das vagas em reserva. Os questionamentos variavam desde saber se estabelecer qualquer "verificação fenotípica" não prevista na Lei de Cotas ou na Portaria Ministerial que regulamenta os procedimentos da citada lei seria ato administrativo que extrapolaria o âmbito das competências administrativas das Universidades Federais, ou se caberia às Universidades utilizar uma interpretação "teleológica" dos dispositivos legais expressos. Tais indefinições resolviam-se na expectativa de que qualquer discussão sobre o sentido da lei de cotas terminaria por ser instalada por meio de ação judicial promovida pelo Ministério Público Federal, com possível repercussão no âmbito nacional, uma vez que se trata de lei federal. Convém ressaltar, desde logo, que, no caso da ACP movida contra a União e a UFC, que será analisada em seguida, o juiz acolheu a preliminar da União de limitação da abrangência da ação exclusivamente à Universidade Federal do Ceará, uma vez que os fatos narrados na 
petição inicial que instaurou o processo se referem à UFC, sem mencionar nem identificar atos específicos de outras universidades pelo Brasil, o que, para o julgador, seria inviável diante da específica realidade de cada instituição de ensino.

Convém frisar que o MEC reforçou em várias ocasiões que a autodeclaração não passará por checagem das instituições federais afetadas pela lei de cotas, uma vez que a política de autodeclaração se afina ao sentido da lei que o Congresso votou. De acordo com o MEC, a regra segue a mesma do IBGE e das diversas ações afirmativas em outros países, e tal foi a orientação do MEC para as Universidades e Institutos Federais.

É possível afirmar que a grande questão estivesse na inserção do termo "pardo", que amplia o espectro de possibilidades de autodeclaração, de certa forma equiparando uma população de negros e indígenas a uma grande quantidade de pessoas que, historicamente, não sofreu as consequências dos já citados impactos da abolição ou não compunha aquela camada da população historicamente excluída na competição social, por um critério adicional de discriminação (a cor). De toda sorte, a determinação de quem poderia definir o enquadramento tornou-se a questão central, como se verá em seguida.

\section{DESAFIOS DE ESTABELECIMENTO: O Questionamento da Autodeclaração}

Quatro episódios divulgados pelos veículos de comunicação no Brasil demonstram que o questionamento da condição de PPI foi experimentado por diversas universidades federais. Os fatos a seguir relatados foram divulgados em sites e jornais de ampla circulação e serão reproduzidos tal como foram descritos.

O jornal Diário do Nordeste, de 16 de maio de 2019, veiculou que a Justiça Federal havia emitido decisão que determinava à Universidade Federal do Ceará (UFC) a elaboração e efetivação de um modelo de controle dos atos administrativos derivados da execução do Programa de Cotas Raciais, tendo por objetivo coibir casos de fraude no modelo de autodeclaração (DIÁRIO DO NORDESTE, 2019). A decisão é resultado de Ação Civil Pública - ACP - ajuizada pelo Ministério Público Federal (MPF), que considera haver um acesso fraudulento de pessoas no Ensino Superior federal por falta de fiscalização da UFC. Conforme a decisão, a universidade tem o prazo de 180 dias para criar uma forma de fiscalizar as autodeclarações raciais no processo de ingresso dos estudantes. O Portal JusBrasil também divulgou a notícia (JUSBRASIL, 2019). O caso da UFC será retomado mais adiante, sendo importante, antes, ressaltar três outras situações que demonstram a recorrência do problema e a diversidade de soluções encontradas pela Administração Pública, especialmente nos procedimentos de heteroidentificação.

Em 14 de junho de 2019 foi noticiado no site da UOL que 56 alunos da Universidade Estadual Paulista (Unesp) decidiram abandonar seus cursos de Graduação naquela semana, depois de saber que precisariam passar por uma entrevista presencial para comprovar que são pretos, pardos ou indígenas. Eles haviam entrado na Unesp por meio do sistema de cotas raciais. Para a universidade, as desistências devem-se ao fato de a fiscalização contra fraudes nas cotas estar mais rigorosa este ano. Na Unesp, metade das vagas é destinada a egressos de escolas públicas. Desse total, $35 \%$ são para quem se autodeclara preto, pardo ou indígena (UOL EDUCAÇÃO, 2019). 
Na Unesp há uma fase da análise sobre o fenótipo dos estudantes candidatos às cotas. Iniciada em janeiro, consiste na apresentação de documentos e no exame de fotos e vídeos dos matriculados. As filmagens que integram o procedimento são feitas durante a realização do vestibular, nas filas e nos corredores dos locais de prova, um procedimento padrão segundo a instituição. Até abril, 1.303 universitários matriculados como cotistas teriam passado pela primeira etapa da averiguação. Desses, 475 não conseguiram comprovar a condição exigida para a reserva de vagas e foram avisados de que haveria mais uma fase de análises. Foi, então, que 56 alunos decidiram não ir mais às aulas e abandonaram seus cursos. Apesar de não generalizar, o grupo de averiguação não tem dúvidas de que a parte deles ficou com receio de não conseguir comprovar as características exigidas pelas cotas. "Essas desistências aconteceram assim que eles foram informados de que passariam por mais uma fase de análise por causa da inconsistência da declaração de pretos, pardos ou indígenas, tendo a crer que eles verificaram a robustez do processo", explicou à reportagem o presidente da Comissão de Averiguação (UOL EDUCAÇÃO, 2019).

De acordo com a reportagem, ainda não foi feito um levantamento sobre de que cursos eram os alunos desistentes. O problema não está apenas no fato de perder o direito à vaga como cotista. Ao final da averiguação, a comissão recomenda o desligamento dos universitários que não passaram pelos critérios do sistema, como aconteceu no ano passado com 27 estudantes da mesma instituição. Se isso acontecer, o aluno perde o direito de concorrer ao vestibular da Unesp por cinco anos. "Quando foram chamados para a segunda fase agora, muitos se anteciparam para evitar que não pudessem fazer vestibular depois e se desligaram", afirmou à reportagem o presidente da Comissão de Averiguação (UOL EDUCAÇÃO, 2019). Como saíram antes do fim do processo, eles podem fazer vestibular na universidade, mas apenas como alunos de escola pública, exigência mínima para tentar entrar pelas cotas e não mais com a condição racial.

A segunda fase da averiguação foi por meio de entrevistas que duram, em média, três minutos, por videoconferência, em 24 cidades onde há cursos da Unesp. Os integrantes da comissão examinaram cor da pele, textura do cabelo e características da boca, nariz, olhos e orelhas. A checagem segue para a última fase com universitários que ainda não conseguiram comprovar o que declararam e que poderão apresentar argumentos, justificar e embasar a autodeclaração. Caso não tenha êxito, o aluno pode ainda entrar com recurso. O presidente da comissão averiguadora afirma que o modo de checagem das características físicas do candidato a cotista é amparado por decisão do Supremo Tribunal Federal de 2012. A forma de trabalho das comissões segue os procedimentos repassados pelo Conselho Nacional do Ministério Público em 2016 e por norma técnica emitida pelo governo federal, a ON no 03/2016 - Ministério do Planejamento, Desenvolvimento e Gestão (MPDG, 2016).

Em 26 de junho de 2019, o jornal O Globo noticiou que o Ministério Público Federal (MPF) do Rio de Janeiro constatou que uma aluna da Universidade Federal do Rio de Janeiro (UFRJ) fraudou o sistema de autodeclaração para se beneficiar de maneira indevida das vantagens oferecidas pelas cotas raciais a alunos pretos, pardos e indígenas. A entidade anunciou que ajuizou uma Ação Civil Pública em caráter liminar para que a matrícula da estudante seja cancelada. O caso também se originou de denúncia. $\mathrm{A}$ 
reportagem transcreve fala do MPF, afirmando que "só age em casos em que há fraude evidente" e que "é importante frisar que casos como estes são isolados" e que o MPF "não está atacando as cotas ou dizendo que elas são desnecessárias", sendo a intenção da instituição ministerial desestimular esse tipo de fraude (O GLOBO, 2019).

Em fevereiro de 2019, prossegue a reportagem, o MPF entrou com pedidos semelhantes para impedir que alunos dos cursos de Direito e Medicina da própria UFRJ e da Universidade Federal do Estado do Rio de Janeiro (Unirio) frequentassem as aulas, citando também que fotos de redes sociais foram utilizadas durante a investigação. Os procuradores, de acordo com a reportagem, são enfáticos ao apontarem negligência no processo seletivo da Universidade, concluindo que a UFRJ contribui diretamente para o esvaziamento e mesmo para a subversão da ação afirmativa sob análise, que o MPF considera importante medida de reparação histórica. A UFRJ informou ao O Globo que criou, em junho de 2019, uma comissão para analisar as autodeclarações de cor. A Universidade, segundo a reportagem, tem outros 50 processos semelhantes.

Em 3 de setembro de 2019, o site de notícias GGN divulgou que a reitora temporária da Universidade Federal de Grande Dourados (UFGD) determinou a reintegração de seis estudantes de medicina desligados por fraude contra a lei de cotas. A medida contrariava a decisão da ex-reitora, que rejeitou todas as tentativas de acordo propostas pelos alunos, e virou alvo de protestos nas redes sociais de membros da comunidade acadêmica. Seis alunos, dois que ingressaram na turma de 2016 e quatro na turma de 2018, foram reintegrados a partir deste segundo semestre de 2019. Todos eles entraram na faculdade por meio da lei de cotas com a chamada "autodeclaração". Na edição do processo seletivo dos estudantes apontados, a UFGD não tinha uma comissão de avaliação étnico-racial (JORNAL GGN, 2019).

A sequência de fatos neste caso é semelhante às demais situações já descritas. Depois de uma série de denúncias sobre alunos que fraudavam suas condições étnicas para ingressar com mais facilidade nos cursos concorridos da Universidade Pública, a instituição criou a comissão de verificação, em março de 2018, que passou a avaliar a autenticidade das declarações feitas pelos candidatos. No caso da UFGD, alguns alunos foram expulsos depois de a comissão constatar o que denominaram de fraude. Seis deles recorreram, mas o Conselho Universitário, formado por 43 representantes da reitoria, dos professores, dos servidores administrativos, dos acadêmicos e da comunidade não acadêmica, negou todos os recursos, mantendo os desligamentos até a primeira semana de setembro, quando, de acordo com a reportagem, a ordem de reintegração foi emitida pela Reitoria. Em nota sobre a defesa da reintegração dos seis alunos de medicina, divulgada no início de setembro, a assessoria da UFGD argumentou que não é mais possível a ocupação das vagas por alunos comprovadamente pretos, pardos e indígenas, e que reintegrar os estudantes seria um ato decorrente da concorrência de culpa da própria Universidade para a ocupação e permanência nas vagas de forma irregular. Os alunos seriam "culpados" por prestarem declarações não compatíveis com a realidade, e a Universidade teria concorrido em culpa por ter demorado para fazer a verificação de veracidade da autodeclaração. 
Ainda de acordo com a nota, "a UFGD já teve gastos relevantes na formação dos alunos, gastos esses que não reverterão em proveitos sociais e demonstram dispêndio de grande monta de recurso público, sem proveito algum para a comunidade", concluindo que os estudantes terão de prestar serviços médicos "não remunerados" semanais de 20 horas "na rede pública de saúde, preferencialmente em bairros pobres da região da Grande Dourados, aldeia indígena de Dourados e Hospital Universitário da UFGD", como "castigo" (JORNAL GGN, 2019).

Os casos analisados desvelam uma dinâmica que envolve não somente a Universidade e seus candidatos à cotista PPI, mas o Ministério Público e o Judiciário, e mesmo à sociedade em geral, considerando que as denúncias de ocupação indevida de vagas em reserva são um fator fundamental para a composição desse cenário. Todos esses elementos fizeram algumas universidades adotarem medidas administrativas complementares, e este artigo examinará mais detalhadamente os desdobramentos dos procedimentos levados a feito pela Universidade Federal do Ceará.

A UFC, depois das notícias veiculadas no Diário do Nordeste e Portal JusBrasil, e tendo tomado conhecimento da sentença proferida na $A C P$, processo judicial $\mathrm{n}$ ㅇ 0803149-12.2018.4.05.8100, julgada pela 3a Vara Federal no Ceará, emitiu uma nota pública, em 15 de julho de 2019, por meio da qual faz uma série de esclarecimentos à sociedade (UFC, 2019). Inicia por afirmar que nos últimos processos seletivos, realizados sob a Lei no 12.711/2012, a ocupação das vagas reservadas para pretos, pardos e indígenas estava condicionada à entrega de uma autodeclaração, assinada pelo candidato, no ato da primeira matrícula. Informa também que os canais de comunicação da UFC com a sociedade, especialmente a Ouvidoria, passaram a receber denúncias de ocupação indevida, que se amiudaram nos três últimos anos. Informa que, por meio de sua Pró-Reitoria de Graduação - Prograd -, passou a dialogar com as demais Universidades Federais para estabelecer um meio de coibir condutas contrárias aos objetivos da Lei de Cotas. A nota comunica que a Procuradoria da República no Ceará, por sua vez, ajuizou a citada Ação Civil Pública, em 2017, também com base em denúncias, para levar a discussão ao Judiciário. Nessa ação, a Universidade, o Ministério Público e o Judiciário puderam, em diálogo, estabelecer um modelo que atendesse às exigências de moralidade que a Universidade entendia se coadunar com a ação pedagógica e transformadora que lhe cabe.

Destaca-se que, ao longo da ação judicial, o MPF no Ceará reforça o argumento usado pela MPF do Rio de Janeiro de que a Universidade estava sendo negligente e concorria para a permissão de ocupação irregular de vagas em reserva por se negar a estabelecer um procedimento complementar à autodeclaração. O pedido do MPF consistia no estabelecimento da obrigação de ter a Universidade um procedimento de controle ao qual se submetessem todos os candidatos à vaga PPI.

Assim, a nota comunica, confirmando o teor das notícias já divulgadas pela mídia e supracitadas, que foi determinado, por meio da sentença judicial, em abril de 2019, que a UFC deveria formular e executar um sistema complementar à autodeclaração. Dessa forma, a UFC estaria adotando o modelo de heteroidentificação, já utilizado nos concursos públicos com reserva de vagas, diminuindo a condição exclusiva e absoluta da autodeclaração. A ocupação de vagas PPI ainda exigiria que o candidato assinasse a 
autodeclaração, mas tal documento poderia ser confrontado com relatório emitido por uma comissão de cinco membros, composta em atenção à diversidade de cor e gênero, que, presencialmente, faria uma identificação fenotípica com os estudantes convocados a partir de denúncias de ocupação irregular. Em caso de divergência entre a autodeclaração e o relatório da comissão de heteroidentificação, ao candidato é facultado solicitar uma segunda verificação por comissão diferente da primeira. Se persistir a divergência, o estudante deverá ter sua matrícula cancelada pelo não enquadramento às condições de cota pleiteada.

No caso da UFC, o procedimento complementar de heteroidentificação ensejou o cancelamento, em agosto de 2019, de 11 matrículas, sendo 8 do curso de Medicina, com a consequente propositura de alguns Mandados de Segurança, conforme se verá adiante. Os argumentos e contra-argumentos serão analisados após a contextualização fática na qual se realizaram os atos administrativos de cancelamento de matrículas.

No caso da primeira sessão de heteroidentificação realizada pela UFC, o procedimento também tinha por objeto 14 denúncias recebidas pelos diversos canais institucionais, especialmente a Ouvidoria, das quais 8 se referiam a alunos do curso de Medicina. Dos estudantes, 2 desistiram da matrícula, e dos 12 presentes à sessão de heteroidentificação apenas 1 teve sua condição de cotista confirmada. As denúncias, como nos demais casos em outras Universidades, sempre vinham acompanhadas de fotografia, provavelmente obtida por meio de acesso às redes sociais.

Como a UFC, a UFRJ e a UFGD passaram a entender o problema da definição de a quem cabe o enquadramento? Inicialmente as Universidades parecem ter sido unânimes em manter o critério da autodeclaração, por entender que foi este o critério que a legislação estabeleceu. Houve, entretanto, uma mudança no entendimento sobre a possibilidade de outros procedimentos de enquadramento, uma vez que a legislação não proibiu que outros procedimentos fossem estabelecidos no cumprimento da política. Resolveu-se, então, pela possibilidade de um procedimento complementar. No caso da UFC, houve mesmo uma decisão judicial que lhe impunha uma obrigação de fazer.

Qual a razão de as Universidades terem estabelecido um procedimento complementar? No início, foram as denúncias, isto é, manifestações da sociedade de desconforto com um enquadramento que se percebia descabido. As Universidades não ficaram indiferentes ao controle social que estava sendo feito sobre a política de cotas, e tornou-se pauta frequente a discussão de quais providências seriam possíveis administrativamente. Esse desconforto, como se viu, foi encampado pelo Ministério Público Federal que, por meio de Ações Civis Públicas, instou o Poder Judiciário a se manifestar. No caso específico da UFC, é possível analisar a própria sentença da ACP no 080314912.2018.4.05.8100 (JUSTIÇA FEDERAL, 2019).

O fundamento do pedido de MPF é a existência da Orientação Normativa - ON no03/2016-MPDG -, que autorizaria, por força de imediata aplicação analógica, as Universidades a estabelecer comissões de heteroidentificação. A referida ON estabelece que a autodeclaração somente fosse considerada válida se os aspectos fenotípicos do candidato forem confirmados presencialmente e que, na hipótese de constatação de autodeclaração falsa, o candidato fosse eliminado do concurso, sem prejuízo de outras 
sanções cabíveis (MPDG, 2016). O julgador define como mérito da ACP a definição de ter a Universidade Federal do Ceará o dever de realizar o controle da veracidade da autodeclaração dos candidatos à cota racial, especialmente em casos de indício de fraude.

Acolhendo parcialmente o pedido, de resto modificado em audiência diante da explicação dada pela Universidade da impossibilidade de um procedimento universal de verificação, o julgador reconheceu e declarou o dever de a Universidade fiscalizar e controlar a validade das autodeclarações em casos excepcionais, quando houvesse denúncia de que o candidato prestou informações falsas. Na fundamentação da decisão, o julgador destaca a existência de dois procedimentos de definição da condição de PPI: um subjetivo e um objetivo. No primeiro caso, a autodeclaração é suficiente; no segundo caso, admite-se uma heterodeterminação da condição de PPI, sendo o sistema constitucional brasileiro compatível com os dois modelos de acordo com o STF. A decisão retirou o caráter absoluto da autodeclaração, permitindo que seja contrastada com um exame externo ou mais objetivo.

O Poder Judiciário, assim, decidiu que a UFC, no uso do poder-dever da Administração Pública, especialmente diante da possibilidade de atos de má-fé, antiéticos e desonestos, elaborasse e efetivasse um procedimento complementar para os casos de denúncia. $\mathrm{O}$ julgador também destacou que os aspectos normativos, procedimentais e institucionais, necessários à instituição de um modelo de controle, não deveriam ser estabelecidos pelo Judiciário, pois isso seria uma afronta à separação de poderes. Ao Judiciário caberia apenas determinar, como obrigação de fazer, que a UFC elaborasse, em um prazo razoável, um modelo de controle administrativo das autodeclarações, a fim de coibir os casos de fraude e cumprir o poder-dever de anular os atos administrativos derivados de comportamentos antiéticos, imorais e abusivos (JUSTIÇA FEDERAL, 2019).

Amparada pela decisão judicial, a UFC estabeleceu um procedimento complementar de heteroidentificação, análogo àquele estabelecido pela União nos casos de concurso público para cargos ligados ao Ministério do Planejamento, por meio da ON no 03/2016-MPDG. Tais procedimentos já foram utilizados pela UFC nos concursos promovidos pela Comissão de Concursos e Vestibular - CCV - para cargos administrativos da UFC, sem que houvesse questionamento judicial.

Assim, a Prograd/UFC iniciou os atos administrativos para que tal procedimento complementar se realizasse: procedeu a um apanhado de todas as denúncias, não tendo havido escolhas arbitrárias. Em seguida, convocou os estudantes denunciados que compareceram à sessão de heteroidentificação realizada por membros designados pela Portaria no 90/2019-Reitor/UFC. A sessão foi devidamente filmada. A comissão produziu os relatórios, cujos resultados foram comunicados aos estudantes participantes, que puderam solicitar uma segunda avaliação por comissão recursal também designada pela Portaria. A revisão ocorreu regularmente, gerando novo relatório de confirmação do não enquadramento, disponibilizado igualmente aos estudantes. Todo esse procedimento administrativo observou, de um lado, o poder-dever da administração de rever seus atos e a discricionariedade administrativa na consecução do interesse público, e, de outro, os princípios de transparência, comunicação dos atos aos interessados, reserva das situações institucionais dos interessados (preservação da intimidade e imagem), tendo sido, inclusive, comunicado ao MPF dos desdobramentos do procedimento. $\mathrm{O}$ 
procedimento encerrou-se na Prograd e foi enviado à Reitoria da UFC, com recomendação de cancelamento da matrícula dos não enquadrados, por ato do reitor, que, efetivamente, determinou o cancelamento das matrículas. Dois estudantes, até o momento do encerramento da pesquisa, tinham conseguido reverter o cancelamento por decisão judicial em sede de Mandado de Segurança.

No que se refere ao critério, a Administração Pública escolheu, dentre os possíveis critérios já pensados para o enquadramento de candidatos cotista, o critério fenotípico, exclusivamente. Não se trata de identificação biopsicossocial: não foram investigados aspectos da vida dos candidatos que revelassem práticas discriminatórias a partir de narrativas pessoais; a Administração Pública se converteria em um tribunal de comoção, decidindo com base nas narrativas que mais emocionassem os membros da comissão; tampouco foi adotado critério de ancestralidade, não sendo investigada a condição de cor dos ascendentes, porque em normativo brasileiro algum se fala do critério de ancestralidade. O critério de "uma gota de sangue" foi estabelecido pelos espanhóis, no século 15, para identificar criptojudeus nas investidas da Inquisição (um oitavo da ascendência, ou a existência de bisavôs), critério que foi posteriormente adotado nas políticas segregacionistas americanas pós Guerra da Secessão Americana, em 1865, e edição da 13a Emenda, que aboliu a escravidão, conforme Karnal (2008). Adotou-se o mesmo critério dos concursos públicos com reserva de vagas: o fenótipo do candidato, exclusivamente. Considerando a impossibilidade de que todos os candidatos autodeclarados PPI passem por uma comissão em razão da exiguidade do calendário acadêmico, conforme acolhido na fundamentação da sentença, combina-se o critério fenotípico com a existência de denúncias de ocupação irregular.

Embora, no caso da UFGD, existiu menção à fraude e "castigo", a UFC apontou outro entendimento, que permite, inclusive, preservar os atos formativos praticados na vigência da matrícula que venha a ser cancelada. A UFC optou pela compreensão de que não se trata de estabelecer um tribunal de exceção, impondo à Universidade a promoção de um julgamento, sendo assim bem mais razoável que não se faça acusação alguma, formal, por parte da administração, de fraude. O entendimento da UFC, por exemplo, é que se está fazendo o mesmo que faz durante seu processo seletivo com os estudantes que solicitam enquadramento como pessoa com deficiência (PCD), quando se confirma o atestado médico (documento entregue na solicitação de matrícula) em uma entrevista presencial com uma equipe de profissionais da saúde. A UFC considerou, até o encerramento dessa pesquisa, que o critério e o documento de autodeclaração possuem presunção de veracidade, que pode, no entanto, ser contrastada por comissão de heteroidentificação. $O$ que mudou foi apenas a condição de incontrastabilidade da autodeclaração, tal como ocorre com o atestado médico no caso de PCD.

Vejam-se agora os argumentos e contra-argumentos específicos apresentados pela UFC no caso dos Mandados de Segurança contra o ato do reitor de cancelamento das matrículas. Os impetrantes utilizam basicamente os mesmos argumentos, que podem ser assim sistematizados: 1. a afirmação de ser o/a impetrante pleiteante de vaga reservada para as cotas PPI e considerar-se enquadrada por razões de ancestralidade, ou por genótipo (avô pardo e pai moreno); 2. trata-se a matrícula de "fato consumado"; 
3. a inobservância pela UFC do edital de seleção; e 4. nulidade dos atos administrativos do procedimento de heteroidentificação que concluíram pela recomendação de cancelamento da matrícula.

Quanto à afirmação de "fato consumado", a Administração contra-argumentou que pode rever de ofício seus procedimentos. Vê-se, também, pela leitura final da fundamentação da decisão judicial da 3ạ Vara Federal, onde consta ser possível "desenvolver algum tipo de procedimento para fazer o controle administrativo" em situações específicas, "ainda que em momento posterior ao processo seletivo para não atrapalhar o calendário de provas e a logística do processo". Na sentença também fica dito que "os aspectos normativos, procedimentais e institucionais necessários à implementação de modelo de controle não devem ser estabelecidos pelo Judiciário, pois isso seria uma afronta à separação de poderes". Na fundamentação da decisão, portanto, dispôs o julgador que "a UFC elabore, em um prazo razoável, um modelo de controle administrativo das autodeclarações, a fim de coibir os casos de fraudes e cumprir o poder-dever de anular os atos administrativos derivados de comportamentos antiéticos, imorais e abusivos" (JUSTIÇA FEDERAL, 2019). Coíbe-se atos futuros, anula-se atos já praticados.

Quanto ao argumento da irretroatividade, verifica-se que as universidades, em geral, estabelecem nos editais dos concursos a possibilidade de revisão dos seus atos. No caso da UFC, há um Edital para cada processo seletivo, por meio dos quais se prescreve que: a Universidade Federal do Ceará reserva-se ao direito de realizar auditorias nos pedidos de enquadramento das cotas mesmo após os pedidos terem sido deferidos em primeira análise. Procedimentos complementares àquele havido na primeira matrícula, portanto, podem ocorrer se a Administração Pública entender que são necessários, estando disso ciente os candidatos desde a publicação do Edital ${ }^{3}$.

Quanto à alegação de fundamento genotípico, a UFC reforça a adoção do critério fenotípico exclusivamente. Até mesmo pelo uso, por analogia, da Orientação Normativa no 03/2016-MPDG que, embora não tenha sido o que sustentou o procedimento, foi o balizamento para o procedimento no que se refere à limitação do reconhecimento fenotípico. $O$ ato, enquanto em sua dinâmica, aproxima-se daquele disciplinado em outros procedimentos administrativos porque não possui uma forma estrita prevista em lei, estando sua forma no campo da discricionariedade administrativa e sua finalidade vinculada ao cumprimento da lei e ao atendimento do interesse público. Cite-se também decisão emitida pelo TRF 4ạ Região que, seguindo a comissão avaliadora da Universidade Federal do Rio Grande do Sul - UFRGS -, negou o direito à vaga à estudante não enquadrada como parda. Na decisão, a desembargadora federal Vivian Josete Pantaleão Caminha confirmou a legalidade de procedimentos como o adotado pela UFRGS "como forma de assegurar que apenas os efetivos beneficiários das cotas raciais instituídas pela lei sejam contemplados, evitando abusos através de declarações falsas" (TRF-4, 2019). Indica ainda que o critério preponderante na política de cotas são os fato-

Como exemplo, conferir UFC. Universidade Federal do Ceará. Edital no 001/2015-PROGRAD/UFC. Processo Seletivo Sisu 10/2015. Art. 27. Ceará, 13 jan. 2015. Disponível em: http://www.sisu.ufc.br/wp-content/uploads/2015/01/ edital-01-2015-prograd-ufc-sisu-2015.pdf. Acesso em: 7 set. 2019 ou UFC. Universidade Federal do Ceará. Edital no 001/2018-PROGRAD/UFC. Processo Seletivo Sisu 1ㅇ/2018. Art. 28. Ceará, 26 jan. 2018. Disponível em: http://www. sisu.ufc.br/wp-content/uploads/2018/01/edital-001-2018-sisu-2018-ufc.pdf. Acesso em: 7 set. 2019. 
res estéticos visíveis (fenótipo) que poderiam ser causas de discriminação na sociedade, e não a ascendência étnico-racial (genótipo). A magistrada posicionou-se ainda no sentido de que a autodeclaração étnico-racial não pode ser absoluta nem soberana e que a análise deve ser realizada em conjunto com outros critérios para conferir a real situação do candidato.

Por fim, o procedimento complementar de heteroidentificação, levado a feito pela UFC, foi concebido como uma fase do procedimento de matrícula, e observou as garantias da comunicação dos atos, prazos e revisões. De acordo com Notas Jurídicas emitidas pela Advocacia-Geral da União (AGU) para tal fim, por solicitação da UFC, foi estabelecida a possibilidade de abertura de um processo administrativo por candidato para apresentação de alegações e documentos, com a garantia do devido processo legal administrativo, do qual independe o encerramento do procedimento de heteroidentificação. O processo administrativo será aberto por protocolo do interessado no exercício do direito legal de petição, e recebido sem qualquer efeito suspensivo da decisão administrativa desafiada, e tramitará de acordo com a Lei 9.784/1999, a Lei Geral dos Processos Administrativos Federais.

Esse entendimento, entretanto, não foi desposado pelo Tribunal Regional Federal - TRF - da 4a Região. Em decisão que concedeu mandado de segurança para garantir a rematrícula de uma estudante da UFRGS no primeiro semestre de 2019 no curso de Medicina, o Tribunal entendeu que, em caso de dúvidas, a comissão de avaliação racial não pode se valer apenas do parecer fenotípico (manifestação visível ou detectável de um genótipo), sendo imprescindível uma análise do histórico familiar e cultural. Tal entendimento deriva da interpretação da declaração de constitucionalidade proferida pelo Supremo Tribunal Federal - STF - quando da apreciação da Lei de Cotas, sendo considerada legítima a autodeclaração do candidato.

A decisão do TRF, por maioria, reformou sentença em que havia mantido o ato administrativo da Universidade Federal que indeferiu o ingresso da impetrante na cota de negros e pardos. A Comissão Permanente de Verificação da Autodeclaração Étnico-Racial da universidade deixou de homologar a autodeclaração por entender que ela não apresentava características físicas de pessoa parda. A desembargadora-relatora, Marga Inge Barth Tessler, negou a apelação da estudante, mas o desembargador Rogério Favreto abriu a divergência e reverteu a manutenção do julgado. Para o desembargador, é ilegal o parecer emitido pela Comissão de Verificação que, de forma sumária, conclua apenas pelo critério da heteroidentificação, sem qualquer fundamentação e sem levar em consideração a autodeclaração da candidata e os documentos juntados por ela. $O$ Acórdão definiu que, "diante da subjetividade que subjaz à definição do grupo racial de uma pessoa por uma comissão avaliadora e havendo dúvida quanto a isso, tem-se que a presunção de veracidade da autodeclaração deve prevalecer" (CONJUR, 2019).

Todos estes aspectos demonstram o tamanho dos desafios que as universidades brasileiras sempre enfrentaram em um país em que o sistema educacional se estruturou, de acordo com Romanelli (2013), com deficiências relativas à falta de oferta suficiente de escolas, a um baixo rendimento do sistema escolar e com uma discriminação social acentuada. 


\section{CONSIDERAÇÕES FINAIS}

A Lei de Cotas representa uma conquista no que diz respeito à construção de uma universidade mais inclusiva e com diversidade de segmentos sociais, sejam determinados pela renda, pela cor ou pela frequência a escolas públicas e particulares, constituindo, assim, uma verdadeira universidade. A promulgação de uma lei deste porte foi precedida de estudos técnicos, alimentados por dados estatísticos colhidos a partir de uma cultura de autoavaliação e gestão que as universidades brasileiras têm procurado adotar nas últimas décadas. Eliminar uma deficiência estrutural, que caracterizava as universidades brasileiras com uma discriminação social acentuada, exige uma política afirmativa e, mais que isso, uma repactuação da sociedade brasileira comprometida com uma inclusão social que diminuirá a desigualdade social no Brasil. Trata-se de uma decisão política que sinaliza essa intenção. Resta acompanhar e analisar os resultados obtidos.

No âmbito das Universidades Federais, a Lei de Cotas exige da administração pública um cuidado rigoroso no exame de documentação e nas tomadas de decisão, determinando um compromisso com a legalidade dos dispositivos a fim de garantir a isonomia e a acessibilidade às vagas de acordo com os critérios normativos. Programas sociais deste porte não deixam de ser experimentos sociais. Será preciso esperar para ver os impactos, acompanhando todos os indicativos de sua efetivação, como a permanência do cotista e sua inserção no mercado de trabalho. Mais uma vez trata-se de um pacto de uma sociedade, uma decisão política que importa na adesão e na compreensão dos seus dispositivos.

Foi observado que as universidades são executoras de uma política afirmativa, a qual os candidatos chamam em seu favor. Daí decorre que não há controvérsia quanto ao fato de que todos os envolvidos - Administração Pública, Ministério Público, impetrante, Judiciário e Sociedade - reconhecem a existência da política e do critério. Isto é, existe o preto, o pardo, o indígena e, portanto, o não preto, o não pardo e o não índio. É uma consequência lógica. É por isso que os estudantes solicitam o enquadramento. A questão de se existem "cores" no Brasil está superada. Existem! E é por isso que os candidatos alegam em seu favor que são pardos ou possuem ancestrais nessa condição.

Não se pode deixar de afirmar que o processo de criação da Lei de Cotas é complexo e está em constante aperfeiçoamento, devendo, pois, a Administração Pública velar para que o procedimento de matrícula e ocupação das vagas torne-se cada vez mais seguro. Pelos casos trazidos para estudo, verifica-se uma diversidade de entendimentos: enquanto a Unesp estabeleceu um procedimento que busca identificar "inconsistência" nas autodeclarações, a UFC refere-se à "divergência" entre a autodeclaração e a heteroidentificação, levada a feito por duas comissões diferentes, e a UFGD apontou a fraude como fundamento do cancelamento das matrículas. O entendimento da UFC permite preservar os atos formativos adquiridos durante a vigência das matrículas, no decorrer do procedimento administrativo de verificação, fase do próprio procedimento de matrícula. A UFGD sustenta um discurso incoerente, quando afirma a existência de fraude e adota como consequência à manutenção dos estudantes e à aplicação de uma 
"sanção de prestação de serviços comunitários" por parte de fraudadores. A Unesp, como se viu, prevê até mesmo uma sanção de impedimento de solicitação de matrícula para candidatos não enquadrados dentro do prazo de cinco anos.

O MPF, por sua vez, investiga casos em que há indícios de fraude e, por dever institucional, poderá promover ações penais cabíveis contra os estudantes, enquanto a sentença judicial analisada usou o termo indício de fraude para caracterizar a conduta a ser coibida pela UFC, que, por sua vez, adotou um entendimento, conforme a ON no 03/2016-MPDG, de que a consequência no âmbito administrativo deverá ser a eliminação do candidato do concurso como a consequência do não enquadramento.

A divergência no acertamento dessas questões decorre de um composto entre $o$ reconhecimento da autonomia universitária, do princípio da universalização da jurisdição, das disposições constitucionais conformadoras da missão institucional do Ministério Público e ainda de um poder-dever da sociedade de fiscalizar o cumprimento de políticas públicas. Todos esses desafios terão oportunidade de serem discutidos na revisão da Lei de Cotas prevista para 2022, quando será possível uma orientação mais uniforme para a resolução dos problemas enfrentados nos primeiros cinco anos de seu estabelecimento.

\section{REFERÊNCIAS}

AGÊNCIA PÚBLICA. EBC. Número de estudantes no Ensino Superior aumenta; maioria ainda é branca e rica. Em 2014 eles somavam 58,5\% do total de estudantes de 18 a 24 anos. 4 dez. 2015. Disponível em: http://agenciabrasil.ebc.com.br/geral/noticia/2015-12/ensino-superior-avanca-25-pontos-percentuais-entre-jovens-estudantes-em-10. Acesso em: 7 set. 2019.

BRASIL. Lei no 12.771, de 29 de agosto de 2012a. Dispõe sobre o ingresso nas universidades federais $e$ nas instituições federais de ensino técnico de nível médio e dá outras providências. Disponível em: http:// www.planalto.gov.br/ccivil_03/_ato2011-2014/2012/lei/l12711.htm. Acesso em: 7 set. 2019.

BRASIL. Decreto no 7.824, de 11 de outubro de 2012b. Regulamenta a Lei no 12.711, de 29 de agosto de 2012, que dispõe sobre o ingresso nas universidades federais e nas instituições federais de ensino técnico de nível médio. Disponível em: http://www.planalto.gov.br/ccivil_03/_ato2011-2014/2012/decreto/ d7824.htm. Acesso em: 7 set. 2019.

BRASIL. Portaria Normativa no 18, de 11 de outubro de 2012c. Dispõe sobre a implementação das reservas de vagas em instituições federais de ensino de que tratam a Lei no 12.711, de 29 de agosto de 2012, e o Decreto no 7.824, de 11 de outubro de 2012. Disponível em: http://portal.mec.gov.br/cotas/docs/ portaria_18.pdf. Acesso em: 7 set. 2019.

CONJUR. Avaliação de fenótipo não derruba autodeclaração de quem opta pelo sistema de cotas. 9 nov. 2019. Disponível em: https://www.conjur.com.br/2019-nov-09/avaliacao-fenotipo-nao-derruba-autodeclaracao-sistema-cotas. Acesso em: 11 nov. 2019.

COSTA, Emília Viotti. A abolição. 9. ed. São Paulo: Unesp, 2010.

DIÁRIO DO NORDESTE. Justiça federal determina que UFC fiscalize autodeclarações raciais. 16 maio 2019. Disponível em: https://diariodonordeste.verdesmares.com.br/editorias/metro/online/justica-federal-determina-que-ufc-fiscalize-autodeclaracoes-raciais-1.2100075. Acesso em: 7 set. 2019.

EBC. Número de alunos no ensino superior ultrapassa 7,3 milhões. 9 set. 2014. Disponível em: http:// www.ebc.com.br/educacao/2014/09/numero-de-matriculados-no-ensino-superior-ultrapassa-73-miIhoes. Acesso em: 20 set. 2019.

FERNANDES, Florestan. A integração do negro na sociedade de classes. São Paulo: Globo, 2008.

FRIAS, Lincoln. As cotas raciais e sociais em universidades púbicas são injustas? Direito, Estado e Sociedade, n. 41, p. 130-156, jul./dez. 2012. Disponível em: http://direitoestadosociedade.jur.puc-rio.br/media/7artigo41.pdf. Acesso em: 7 set. 2019.

JORNAL GGN. Recém nomeada por Weintraub, reitora da UFDG beneficia alunos que fraudaram cotas. 3 set. 2019. Disponível em: https://jornalggn.com.br/justica/recem-nomeada-por-weintraub-reitora-da-ufgd-beneficia-alunos-que-fraudaram-cotas/. Acesso em: 7 set. 19. 
JUSBRASIL. MPF obtém decisão que obriga UFC a fiscalizar autodeclarações raciais. Maio 2019. Disponível em: https://mpf.jusbrasil.com.br/noticias/709236158/mpf-obtem-decisao-que-obriga-ufc-a-fiscalizar-autodeclaracoes-raciais. Acesso em: 7 set. 2019.

JUSTIÇA FEDERAL. Processo no 0803149-12.2018.4.05.8100. Ação Civil Pública. 3a Vara Federal. Relator: George Marmelstein Lima. Ceará, 16 maio 2019. Disponível em: http://www.mpf.mp.br/ce/sala-deimprensa/docs/acao-fiscalizacao-de-autodeclaracoes. Acesso em: 7 set. 2019.

KARNAL, Leandro et al. História dos Estados Unidos: das origens ao século XXI. 2. ed. São Paulo: Contexto, 2008.

O GLOBO. MPF encontra novo caso de fraude em cotas raciais da UFRJ e pede cancelamento de matrícula. 26 jun. 2019. Disponível em: https://oglobo.globo.com/sociedade/educacao/mpf-encontra-novo-caso-de-fraude-em-cotas-raciais-da-ufrj-pede-cancelamento-de-matricula-23766327?utm_source=WhatsApp\&utm_medium=Social\&utm_campaign=compartilhar. Acesso em: 7 set. 2019.

NEC. Ministério da Educação. Entenda as cotas para quem estudou todo o ensino médio em escolas públicas. 2012a. Disponível em: http://portal.mec.gov.br/cotas/sobre-sistema.html. Acesso em: 7 set. 2019. MEC. Ministério da Educação. Decreto que regulamenta Lei de Cotas passa por redação final. 9 out 2012b. Disponível em: http://portal.mec.gov.br/cotas/sobre-sistema.html. Acesso em: 7 set. 2019.

MPDG. Ministério do Planejamento, Desenvolvimento e Gestão. Orientação Normativa no 3, de 1ㅇde agosto de 2016. Dispõe sobre regras de aferição da veracidade da autodeclaração prestada por candidatos negros para fins do disposto na Lei no 12.990, de 9 de junho de 2014. Disponível em: http://www. in.gov.br/materia/-/asset_publisher/Kujrw0TZC2Mb/content/id/23376081/do1-2016-08-02-orientacao-normativa-n-3-de-1-de-agosto-de-2016-23375906. Acesso em: 7 set. 2019.

ROMANELLI, Otaíza de Oliveira. História da Educação no Brasil (1930-1973). 39. ed. Petrópolis: Vozes, 2013.

SANTOS, Boaventura de Sousa. A Universidade no século XXI: para uma reforma democrática e emancipatória da universidade. 3. ed. São Paulo: Cortez, 2011. (Coleção questões da nossa época; v. 11).

SOUSA JÚNIOR, José Geraldo (org.). Da universidade necessária à universidade emancipatória. Brasília: Editora Universidade de Brasília, 2012.

SOUZA, Jessé. A tolice da inteligência brasileira: ou como o país se deixa manipular pela elite. São Paulo: LeYa, 2015.

TRIBUNAL REGIONAL FEDERAL 4 (TFR-4). TRF4 mantém autonomia de comissão avaliadora de cotas raciais da UFRGS. 31 jul. 2019. Disponível em: https://www.trf4.jus.br/trf4/controlador.php?acao=noticia_ visualizar\&id_noticia=14646. Acesso em: 7 set. 2019.

UFC. Universidade Federal do Ceará. Nota à Sociedade: ocupação das vagas reservadas para estudantes pretos, pardos e indígenas. Disponível em: http://www.ufc.br/noticias/13265-nota-a-sociedade-ocupacao-das-vagas-reservadas-para-estudantes-pretos-pardos-e-indigenas. Acesso em: 7 set. 2019.

UOL EDUCAÇÃO. Após Unesp exigir prova para cotas raciais, 56 estudantes abandonam cursos. 14 jun. 2019. Disponível em: https://educacao.uol.com.br/noticias/2019/06/14/estudantes-unesp-abandonam-cursos-analise-de-cotas-raciais.htm. Acesso em: 7 set. 2019. 